\title{
Study on Emergency Management System of Food Safety
}

\author{
Sixi Peng ${ }^{1, \text { a, }}$, Xiuli $\mathrm{Hu}^{2, \mathrm{~b}}$ \\ ${ }^{1}$ College of Economics \& Management, South China Agricultural University,Guangzhou, China; \\ ${ }^{2}$ Department of asset management, Guangzhou Panyu Polytechnic Institute,Guangzhou, China; \\ a pengsixi@scau.edu.cn, b827001643@qq.com \\ *corresponding author
}

Keywords: food safety, emergency treatment, food safety crisis, crisis early warning.

\begin{abstract}
How to build a comprehensive emergency management system of food safety crisis is an urgent issue when frequently happening of food safety crises make the issue of crisis management become more and more prominent. This article makes a research on China's food safety crisis emergency treatment based on our country national condition and foreign experience. For food safety crisis treated scientifically according to the rules, the article constructs the emergency treatment system from four aspects of crisis early warning mechanism, organizational mechanism, job specification mechanism and safety mechanism.
\end{abstract}

\section{Introduction}

How to build a comprehensive emergency management system of food safety crisis is an urgent issue when frequently happening of food safety crises make the issue of crisis management become more and more prominent. From Sanlu milk powder incident, we can see that in response to food safety crisis, since lacks sound laws and regulations, emergency management procedures and scientific approaches, the local government has no idea what to do, or miss the best chance, resulting in disharmony of local social life. Government departments, as the main body of food safety emergency management, its responsibilities, organizational system, mode, ability and effectiveness of Co-governance, and establishment of law authority exist many problems that cannot be ignored ${ }^{[1,2]}$. Therefore, this article makes a research on China's food safety crisis emergency treatment based on our country national condition and foreign experience.

\section{Problems Existing in Food Safety Crisis Emergency System}

\subsection{Lack of Sound Legal Protection}

First, most of the legislation related to food safety emergency management lacks operability. The legislation of food safety crisis emergency management has granted institutions rights of emergency treatment, but ignored the control of power and legal relief caused by the rights. Second, legal norms of the existing food safety crisis management have been carried out incompletely, mostly displayed by practicing lawlessness, lax enforcement, administrative nonfeasance and neglect of duty, etc. Finally, no uniform law of food safety crisis management has been legislated, although the "Food Safety Law of PRC" briefly mentioned five principle provisions ${ }^{[3]}$.

\subsection{Lack of Independent Permanent Comprehensive Coordination Mechanism}

For now, the government mechanism in charge of food safety crisis emergency management is temporary agencies set up by the State Council or local governments, such as the Food Safety Incidents Command Institution. They are temporary, and most of them do not have their own separate agencies, and leave routine work to related permanent departments. As lack of specialized 
food safety crisis emergency management agencies, the government is passive, hasty and slow to effectively identify, confirm and deal with crisis, and seems to struggle for the integration of social resources, comprehensive coordination of various government departments.

\subsection{Lack of Information Disclosure and Communication}

System parameter in the process of emergency management of food safety crisis, the destructiveness and lethality caused by rumors and panic should not be underestimated, which is due to the lack of formal release information system [ ${ }^{4]}$. If the normal information is closed, the news got by public will certainly be distorted, and the rumors will spread, leading to further exacerbate the panic and spawn events affecting social stability.

\subsection{Lack of Folk and Social Participation}

China's food safety crisis management is unidirectional, top-down, dominated by control and command, which is not suitable for modern emergency management with the rapid development of social economy for decades. Social participation is almost remained on the primary stage such as donations funded and have failed to put into great play. So, in the construction of emergency management system, the government must take social folk force (volunteer organizations, private sector, international assistance, etc.) into the system.

\section{Foreign Emergency Management System of Food Safety Crisis: Experiences and Lessons}

\subsection{Emergency Treatment System of Food Safety Crisis in the United States}

(1) The systematic, comprehensive laws and regulations of food safety system: To standardize enterprise, group and individual's behavior in the United States there are 35 federal laws and regulations in response to food safety, covering all crisis incidents in food categories and food chain, which provides an effective basis and work for developing regulatory policy and scientific prevention of food safety crisis. The national laws make a contribution to clear the legal responsibility of relevant individuals and organizations in the food safety, preventing and reducing the happening of food safety crisis and its damage to public ${ }^{[5]}$.

(2) Sound Organizational Structure: Traditional public health system in the United States took the "country - state -region" three public health sectors as the framework. The three-level response system from top to bottom comprises three subsystems: CDC (federal)Disease Control and Prevention System-HRSA (Region/State) Hospital Emergency Preparedness Systems-MMRS (local)Metropolis Medical Emergency System. CDC is a department of the Ministry of Health, which is mainly responsible for the formulation of national food safety control and prevention strategies, public food hygiene monitoring and early warning, emergency response, resource integration and training of managers and staffs in public food hygiene field. HRSA, parallel with the CDC, belongs to the Ministry of Health. It develops region's ability to respond to the food safety crisis mainly by improving the emergency response capacity of hospitals, outpatient centers, and other cooperation in health sector. MMRS is an operation system on the local level to deal with food safety crisis. It ensures the local city cope with effectively within the first 48 hours, and is able to control the situation of the crisis by its own force through collaboration and interaction among local law enforcement agencies, fire departments, natural disaster treatment departments, hospitals, public health agencies and the first on-site personnel.

(3) Orderly and Efficient Operation System: The U.S. food safety crisis emergency management system is a multi-dimensional, multi-field integrated linkage and collaboration system, including public health, emergency management, law enforcement, medical services, and the first on-site personnel. In terms of dealing with food safety crisis, emergency operating system takes measures mainly include:

a. Using the mechanism of the emergency operations center to be launched an investigation into the crisis causes and control measures. 
b. Based on obtaining information timely, using the emergency response plan to develop and update relevant emergency management preparedness guide and control process.

c. Utilizing the interdepartmental emergency coordination plan to enhance information exchanges and countermeasures study, and report layer-by-layer.

d. Informing all levels of governments and their health sectors to enhance prevention and information feedback thought "State and Local Government Relations Partner Network".

e. Releasing the emergency management information of food safety crisis through "Health Information Notification System”.

f. Starting "laboratory network" to mobilize all forces to carry out food safety inspection and scientific research.

g. Forming a special investigation group of food safety crisis, seek the crisis formation, learn the situation, and develop targeted preventive measures against large-scale spread.

h. Developing and updating a set of work and health prevention guides, including diagnosis, investigation, laboratory research and prevention link, to make investigators and researchers have rules to follow, and to prevent secondary pollution.

\subsection{Emergency Treatment System of Food Safety Crisis in EU}

(1) In the process of BSE crisis emergency management, the European Commission realized that the current food safety crisis response and laws and regulations construction have existed obvious defects. Only if setting up a highly independent food safety institution and updating existing food safety regulations will it offer protection to achieve a high level of food safety emergency management. Since the 1990s, the European Union has passed a series of laws and regulations about food safety, animal feed, genetically modified foods, environmental protection, trade restrictions and ban, etc. to protect the interests of consumers. On the other hand, the pass of 178/2002/Ec rules of European Council contribute to make a European unified food law, and made clear requirements to the institutional arrangements of the EU food safety crisis emergency management and the permission of the European Commission.

(2) Permanent Decision-making Advisory Institution: The European Union has established a permanent and independent institution-Food Safety Authority, which fully reflects its great importance to the role of decision-making advisory. The Food Safety Authority can provide decision advice to not only the European Commission and other crisis management institutions, but also the Council, Parliament and other institutions. Establishment of the Food Safety Authority, on the other hand, separated the management and evaluation of the EU's food safety crisis, which created favorable conditions for the advisory body to provide objective, scientific decision-making advice.

(3) Effective Coordination Mechanism: The 178/2002/EC rule of Council and Parliament stipulates that, 15 members in the Food Safety Crisis Management Committee must include one European Commission representative and four officers with the background of protecting the interests of consumers and servicing the food safety organizations. The arrangements above are for communication and coordination between institutions: to strengthen coordination between the assessment and management agencies and to guarantee the coordination operation within Food Safety Authority. Meanwhile, Advisory Meeting set up by EU institutionalized and normalized the coordination between the EU and its member countries and among its member countries, creating conditions for the parties to coordinate their positions and common actions.

(4) Long-term and Institutionalized Emergency Management: Food Safety Authority as the core part of the EU Food Safety Crisis Management System is always on the alert. The basic starting point of the arrangement made by the EU is to deal with the occasional food safety crises with this permanent institutional arrangement. Under crisis conditions, the Food Safety Authority should provide decision-making consultation for the EU institutions and member countries and technical assistance for the Commission if necessary. The establishment and effective operation of the Food Safety Authority provide necessary support for the early effective prevention and control in EU. 


\section{Construction of Emergency Treatment System of Food Safety Crisis}

\subsection{Crises Early Warning Mechanism}

The ideal state of food safety crisis management should detect the hidden hazards of food safety crises in time, and restrain it in the bud. Early warning mechanisms include three aspects:

(1) Primary Food Regulatory Agencies Should Detect Food Safety Hazards in Time: Primary food safety regulation is the basis of food safety early warning. Only if primary safety supervision works well, can it provide necessary information for the food safety early warning, and thus prevents effectively.

(2) Improve Information Reporting System: Food safety early warning is based on large amounts of data, information and materials. Primary food regulatory authorities are information collectors and detectors of food safety crisis. Once noticed food safety crises or hidden hazards, they should report in the shortest possible time to centralized supervision department and primary government, and respectively report to upper management department and government.

(3) Improve Regulatory System of Upper Government Departments on Food Safety Issues: It takes time from detecting food safety hazards to erupt a certain scale food safety crisis, which provides possibility for timely intervention of primary and upper government departments. After food safety hazards is found, primary government regulator should control and certificate actively, and upper government department should supervise over the food safety hazards and especially, primary government regulator's actions, to ensure that food safety risks is under control in time.

\subsection{Organizational Mechanism of Food Safety Crisis Emergency Treatment}

Generally, organizational system of food safety crisis emergency treatment consists of government department, non-governmental organization, business organization, media organization, societal public and international community ${ }^{[6]}$.

(1) Government Department: Government is undoubtedly the leader in food safety crisis management. First, establish a core headquarters responsible for command and deployment of important work in the emergency treatment. Second, set up a series of auxiliary departments specifically responsible for implementation and operation of emergency work in their respective profession field. Third, maintain coordination linkage with other levels governments and the central government. The close cooperation and high coordination in this mode is the key to success of food safety emergency treatment.

(2) Media Organization: The news media plays a huge role in the emergency treatment: firstly, transmit information timely and accurately, thus eliminate rumors and let the public know the truth; secondly, unify public opinion, guide public sentiment, and eliminate social panic, social discontent, social anger, and social rebellion; thirdly, set public opinion, maintain a good image of government, promote smooth crisis management, and maintain social stability.

(3) Non-governmental Organization (NGO): NGO such as social grassroots community, association and commonweal organization is organized with flat network structure. As social autonomous organizations, they combine closely with civil society. They transmit crisis information through a variety of channels, collect social resources, mobilize public participation in response to crisis, relax public mental, maintain social stability, give a hand to the disadvantaged groups, use their own professional advantage to rescue crisis directly, assist and supervise government's crisis response policies and implementation of measurements.

\subsection{Job Specification Mechanism of Food Safety Crisis Emergency Treatment}

In the process of "prevention-emergency treatment-permanent solution", government should start a complete set of normative, reasonable, fast and efficient specification mechanism of emergency treatment in time.

(1) Work Procedure: The standardized emergency treatment procedure is the premise and guarantee of orderly and efficient emergency treatment. Emergency treatment procedures of food 
safety crisis includes: incident investigation, food recall, suspend production for rectification, peer check, and medical treatment.

(2) Work System: It manifests as emergency communication system internally and emergency treatment information release system externally. Emergency communication system includes two aspects: one is the joint conference system, which clear authorities and responsibilities of relevant departments; the other is a standardized communication system, which can overcome communication barriers among departments, save communication time and improve accuracy. Standardized communication takes formatted questionnaires, reports, records, etc. Emergency treatment information release system also includes two aspects: one is that information should be quick and transparent. The other is that the information should be authoritative and unified. To maintain social stability, it is necessary to issue authoritative and unified information by government.

(3) Work Method: For work method, emergency treatment are generally divided into administrative method, legal method, economic method and ideological education method. Work method should take administrative method as the main means, economic method as the auxiliary means, strengthen the application of motivation. Administrative method, the most common method in crisis management, is supported by national executive powers, marked with enforcing decrees, based on hierarchical subordinate affiliation in administrative organs. Economic method is auxiliary in crisis management, based on economic laws, driven by material benefits adjustment, had various ways, in favor of meeting pursuit of management objects' material interests and the need of social interests, against the balance in the social distribution and deviation from the objectives of administrative decision-making, even fail. Incentive method includes reward and punishment. Reward, as a measurement to glow people's sense of honor and aggressive, can mobilize the enthusiasm of administrative staff and manager, maximize their potential capacity. Punishment is to deter and prevent the occurrence of irregularities of administrative staff and manager.

\subsection{Security Mechanism of Food Safety Crisis}

It is particularly important for food safety crisis management to build up a comprehensive and three-dimensional emergency treatment support system.

(1) Human Resource Support: Emergency treatment process of food safety crisis is inseparable from the professionals, whatever in scientific research, on-site disposal or medical aid. Therefore, construction of human resources in food safety crisis management teams should be regarded as a long-term task, to ensure the structure, function, wisdom, experience, professionalism, and coordination and cooperation ability. Professional team of food safety crisis response should include: decision commanding officers, staff consultants, experts in food safety field and logistical support staffs.

(2) Finance Support: Objectively speaking, there is not a systematic, sound emergency finance support system. The government is always trying its best to allocate money after crisis occurs, lack of stable, sustained budget. The foreign crises finance support system consists of three main parts: financial funds, insurance funds, donated funds, which have played a huge role in crisis management ${ }^{[7]}$.

(3) Material Support: Emergency material supplies is a fundamental component in crisis management system, which includes various relief, emergency facilities and equipment and emergency rescue special places required in the early warning, rescue and recovery links. When crisis occurs, whether the relief is able to be delivered quickly to the scene determines the success or failure of emergency management. Therefore, it is important to do routine work of material resources integration. First, enhance emergency supplies information sharing mechanism. Second, improve the rapid response mechanism for emergency supplies and distribution. Third, enhance emergency supplies support mechanism.

(4) Legal Support: National Food and Drug Administration is authorized by law to regulate food safety. As China's food safety laws and regulations are incomplete, standards of food safety is low, level of retribution in food laws and regulations is inadequate, the responsibilities in law 
enforcement link are unclear and lack of supervision, it cannot fundamentally solve problems existing in food safety management in China, such as "soft provisions, weak enforcement, dispersed functions and market management confusion" ${ }^{[8]}$. Therefore, government should make appropriate adjustments to food safety law as below: improve China's food safety control standards; expand the coverage of food standards; pay attention to commonly used animal and plant food safety issues; form a supporting food safety legal system as soon as possible.

(5) Ideological Support: China's food safety education is incomplete now. Education contents should include: public food safety knowledge popularization education; education and training for food practitioners; innovative advanced studies personnel training in food safety field.

\section{Conclusion}

China has entered a period of comprehensive differentiation in the social structure. With social transformation, varying degrees of crises takes place almost in every field. In all kinds of crises, the frequency and negative impact in food safety field is top the list, which brings irreparable loss of life and health. To construct a harmonious and people-oriented society in China, the urgency and importance of the establishment of the food safety crisis emergency treatment mechanism is selfevident.

However, as the main body of food safety emergency management, China's government department still exist many problems that cannot be ignored, such as its function, organizational system, governance model, governance capability, the authority of law. In this paper, in view of the problems existing in China's food safety crisis emergency treatment, draw lessons from foreign experience, to explore how to build up an emergency treatment system of food safety crisis fit in China's national conditions, which has important significance for strengthening food safety management in China.

\section{Acknowledgments}

This work was financially supported by Guangdong soft science research project(2015A0707040 4) and the Project of philosophy and Social Sciences in Guangzhou(2017GZYB39).

\section{References}

[1]. Li Yingqing. Study on Government Emergency Treatment Mechanism in Safety Crisis Management [D] Shanghai: Fudan University, 2009.

[2]. Huang Hanqi and Zhang Chan. Observation on Government's Food Safety Regulators from Sanlu Milk Powder Incident. Hubei University of Economics, 2010 (1) :75-77.

[3]. Liu Zhuo. Study on Government Regulation in China's Food Safety Field-Based on the Thinking of the Sanlu Milk Powder Incident [D]. Hubei University, 2009.

[4]. Li Yu. Implementation Status and Development Trend of Food Safety Control System GMP [J] modern commerce industry, 2010, (3) :28-29

[5]. Mark W. Rosegrant and Claudia Ringler. World food markets into the 21stCentury: environmental and resource constraints and Policies. The Australian Journal of Agricultural and Resources Economies, 2008 (3) :41-15.

[6]. Wang Jianming, Guo Linhai. Observation on China Food Safety Problems and Countermeasures in View of Food Regulatory System in Developed Countries[J]. China's food additives, 2009, (l) :59-60

[7]. Zhao Xinguo, Feng Qiaobin, Liu Min. Finance Support in Emergency Management System: Status and Suggestions[J] Science and Technology for Development, 2010 (3) :43-49

[8]. Gao Guangliang. Perfection of the Food Safety Legal System. Special zone economy, 2017

(7) :236-237 